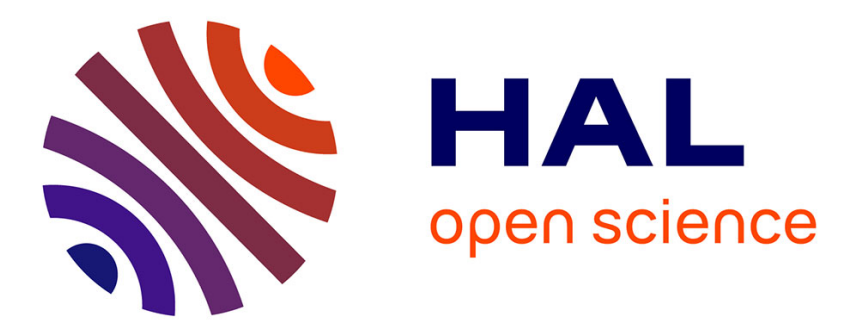

\title{
Monetary incentives in the loss domain and behavior toward risk: An experimental comparison of three reward schemes including real losses \\ Nathalie Etchart-Vincent, Olivier L'Haridon
}

\section{- To cite this version:}

Nathalie Etchart-Vincent, Olivier L'Haridon. Monetary incentives in the loss domain and behavior toward risk: An experimental comparison of three reward schemes including real losses. Journal of Risk and Uncertainty, 2011, 42 (1), pp.61-83. 10.1007/s11166-010-9110-0 . hal-00742027

\section{HAL Id: hal-00742027 \\ https://hal.science/hal-00742027}

Submitted on 18 Oct 2012

HAL is a multi-disciplinary open access archive for the deposit and dissemination of scientific research documents, whether they are published or not. The documents may come from teaching and research institutions in France or abroad, or from public or private research centers.
L'archive ouverte pluridisciplinaire HAL, est destinée au dépôt et à la diffusion de documents scientifiques de niveau recherche, publiés ou non, émanant des établissements d'enseignement et de recherche français ou étrangers, des laboratoires publics ou privés. 


\title{
Monetary Incentives in the Loss Domain and Behavior toward Risk: An Experimental Comparison of Three Reward Schemes Including Real Losses
}

\author{
Nathalie Etchart-Vincent* \\ CNRS, CES-Antenne de Cachan \\ Ecole Normale Supérieure de Cachan \\ 61 Avenue du Président Wilson \\ 94235 Cachan Cedex, France
}

Olivier l'Haridon

GREG-HEC and University Paris Sorbonne.

1 rue de la Libération, 78501 Jouy-en-Josas, France

JEL: C91, D81

\begin{abstract}
The question of whether monetary incentives are necessary to run an experimental study properly is still under debate. In the loss domain, both practical and ethical considerations rule out the systematic use of an incentive-compatible procedure involving real losses, and call for the recourse to some other payment scheme. The experimental study presented here aims at investigating whether some easier-to-implement procedure could be adequately used. For that purpose, the subjects' degree of risk aversion in the loss domain is compared across three payment conditions: a "real losses" condition based on a randomlottery (incentive-compatible) system, which serves as a benchmark, and two challengers, namely a "losses-from-an-initial-endowment" procedure and a "hypothetical losses" condition. The main two points investigated here are 1) whether hypothetical losses could be effectively used in place of a performance-based payment scheme, and 2) whether the lossesfrom-an-initial endowment procedure could be viewed as a legitimate substitute for the real losses one. As a by-product, our experimental design also allows us to investigate the impact of monetary incentives on behavior under risk in the gain domain. The main results are twofold: (i) No significant difference arises between the three payment conditions in the loss domain, except that utility appears to be slightly more convex in the real losses condition; (ii) Significant difference arises between real and hypothetical choices in the gain domain. Our results suggest that the use of monetary incentives may be more crucial in the gain domain than in the loss domain.
\end{abstract}

* Corresponding author. E-mail address: nathalie.etchart-vincent@ens-cachan.fr. Tel: +331 474074 59; fax: +33147402469.

We are grateful to Mohammed Abdellaoui, Aurélien Baillon, Han Bleichrodt and Peter Wakker for their insightful comments on the paper. We also thank the editor as well as an anonymous referee for their highly valuable comments and suggestions. The authors acknowledge the support of Research Grant ANR05-BLAN-0345 from the French National Research Agency. 


\section{Introduction}

The use of monetary incentives in experimental settings has often been considered as a drawing line between economics and psychology. The usual argument that motivates the use of monetary incentives in experiments is that, as for any homo economicus, a subject will neither think nor work hard unless she is paid, and sufficiently paid, for doing so (Davis and Holt 1993; Gibbons 1997; Harrison 1994; Hertwig and Ortmann 2001, 2002; Lazear 2000; Smith 1976; Smith and Levin 1996). Furthermore, paying the subjects is not enough; they must also be paid according to their performance. In this respect, hypothetical choices are assumed to be unrealistic and to result in meaningless, thus unreliable, data (Cox and Grether 1996; Harrison 1994; Harrison 2006 and the references therein). In order to prevent the hypothetical bias, a performance-based procedure has to be introduced so that the subjects feel encouraged to provide an adequate level of effort and to answer sincerely and thoughtfully.

A large body of experimental literature has been devoted to the question of whether monetary incentives actually fulfill their role as an incentive or not and the findings appear to be rather contradictory (Camerer and Hogarth 1999; Read 2005). Besides, most of those studies concern the gain domain. However, investigating the role of monetary incentives in the loss domain could be of great interest and pave the way for more experiments involving losses in the future. Indeed, experiments in the loss domain appear to suffer from a paradox. On the one hand, many real-world decisions involve (risky) losses, so that it appears crucial to investigate behavior in the loss domain more widely. Yet, up to now there have been very few experimental studies conducted in the loss domain. In our opinion, this may be due in part to the fact that it is difficult to introduce an appropriate performance-based reward scheme when losses are involved. 
More specifically, experimentalists who are interested in losses are faced with a serious dilemma. On the one hand, they can not, for ethical reasons, make subjects lose for real. ${ }^{1}$ And they may find it difficult to recruit subjects prepared to lose money from their own pocket without subjecting their sample to a strong selection bias. $^{2}$ On the other hand, the scientific legitimacy of an experimental study in economics may be put into question if it does not introduce real decisions. A compromise consists in giving the subject an initial endowment from which she may lose for real without losing her own money (see for instance Mason et al. 2005 , p. 189 , note 4 , for a pragmatic justification of the procedure). Though widely used, this "losses-from-an-initial-endowment" procedure has been criticized from a theoretical viewpoint since it may induce two opposing undesirable effects (Thaler and Johnson 1990). First, the subject may not consider such "covered" losses as real: she may be tempted to play with the house money as if it were a manna. This is the so-called "house money" effect, which tends to enhance risk seeking. However, this house money effect may be dampened if the subject views the initial endowment as a reward obtained in return for some effort (even that provided during a trivial task), instead of a manna. Second, the subject may integrate the initial endowment into the subsequent potential losses. This is the "prospect-theory-withmemory" effect, which means that the subject will keep the initial endowment in mind when

\footnotetext{
${ }^{1}$ To counter this difficulty, Schoemaker (1990) introduced an ingenious procedure. At the beginning of the experiment, the subjects were informed that 7 of them would be selected at random at the end of the experiment and asked to play a loss lottery (selected at random too) for real. But at the end of the experiment, after playing the lottery for real, they were told that they would actually not lose any money. Obviously, while involving genuine monetary incentives (since the subjects did expect to lose real money when making their choices), such an experimental design remains ethically acceptable (since the subjects did actually not incur any real loss). But the price to pay is rather high. First, it is based on subjects' deception, which conflicts with the norms of honesty and trust that prevail in economics (see Bardsley 2000 for instance; it is worth pointing out Bardsley's proposal of a new experimental design, called the Conditional Information Lottery, that "offers all the benefits of deception without actually deceiving anyone", p. 215). Second, it may dampen the credibility of further experiments involving losses and prevent the subjects from trusting the experimenter. Third, it may be hard to replicate: the subjects may not believe the experimenter who tells them that they may lose for real at the end of the experiment, which prevents the payment scheme from being efficient.

${ }^{2}$ Thaler and Johnson (1990) first introduced a small probability of losing for real, but their subject pool (based on voluntary participation) was strongly biased toward risk seeking. So they modified their experimental design to make the experiment more attractive for risk averse people: (1) the probability of losing money was made very small $(0.04)$; (2) the subjects were told that they would be allowed to take part in another experiment after the current one so that they could recover their losses in case they previously lose money; (3) the subjects were told that those who would have lost money at the end of those two experiments would be given a bonus. It was then possible to recruit risk averse subjects, but the experiment did actually no longer involve real losses.
} 
making subsequent decisions. For example, consider an initial endowment of $€ 20$, a fair coin toss and the following gamble: if the toss lands head, $€ 10$ are lost; if the toss lands tail, nothing is lost. If the subject integrates the initial endowment into the subsequent losses, then she may deal with the preceding gamble as if it offered a $€ 10$ gain if the toss lands head and a $€ 20$ gain if the toss lands tail. So, she may behave as if she were faced with a gain choice situation rather than with a loss one. As many people have been shown to exhibit risk seeking in the loss domain but risk aversion in the gain domain, the prospect-theory-with-memory effect may bias behavior toward risk aversion.

Empirically, the findings appear not to be clear-cut. Several studies actually support the house money effect (Arkes and Blumer 1985; Gärling and Romanus 1997; Keasy and Moon 1996; Romanus, Hassing and Gärling 1996; Thaler and Johnson 1990; Weber and Zuchel 2001; see however Clark 2002 for somewhat contradictory results, and Harrison 2007 for a critical discussion of Clark's statistics). Conversely, some studies suggest that the losses-from-aninitial-endowment procedure tends to increase the subjects' level of risk aversion (Arkes, Herren and Isen 1988; Isen and Patrick 1983), bringing some support to the prospect-theorywith-memory effect.

Our study aims to systematically explore whether subjects' risk aversion over losses depends on the payment scheme. Our experimental design confronts the participants with real losses. In this respect, note that what we call "real losses" here is not based on a single choice loss situation as in a number of earlier papers (Beattie and Loomes 1997; Cubitt, Starmer and Sugden 1998; Starmer and Sugden 1991). Most of the time, real losses cannot be used because most experimental studies require many preferences to be elicited. Consequently, we chose to ground our real losses condition on the (incentive-compatible) random-lottery payment scheme. This payment scheme has become a standard when choice between simple 
lotteries is involved (Holt 1986; Starmer and Sugden 1991; Cubitt, Starmer and Sugden 1998; Lee 2008; Baltussen, Post, van den Assem and Wakker 2008).

The random-lottery real losses condition was introduced as a benchmark, allowing us to investigate the relative efficiency of two alternative payment conditions involving losses. The first one was the above-mentioned losses-from-an-initial-endowment (or "covered losses") procedure. The second one was a "hypothetical losses" condition, with no performance-based payment (subjects were only paid a flat-fee for taking part in the experiment ${ }^{3}$ ). Two additional payment schemes were also introduced in the experimental design, namely a "hypothetical gains" and a "real gains" condition. The "real gains" condition was introduced so that we could test the prospect-theory-with-memory effect (by comparison with the "losses-from-aninitial-endowment" condition). The "hypothetical gains" condition was introduced so that we could test the hypothetical bias in the gain domain (by comparison with the real gains condition), allowing us to get a broader picture of the hypothetical bias across domains. On the whole, the experiment thus involved five different treatments.

Each treatment involved the same kind of task for the subjects, who only had to choose between simple lotteries (namely a binary one and a degenerate one) involving either gains or losses. For each subject, collected data were then used to compute her certainty equivalent for each binary lottery under consideration, enabling us to get some information about her risk attitude. Assuming rank-dependent utility (RDU) or prospect-theory (PT) preferences, this also allowed us to estimate the components of her risk attitude, namely her utility and probability weighting functions. ${ }^{4}$

The main results of the study are twofold. First, the subjects did not appear to exhibit a significantly different pattern of behavior depending on the payment scheme in the loss

\footnotetext{
${ }^{3}$ Note that such a kind of hypothetical choices has been widely used in experiments involving individual decision making under risk when losses are at stake (Abdellaoui 2000; Etchart-Vincent 2004, 2009; Fennema and Van Assen 1999; Abdellaoui, Bleichrodt and Paraschiv 2007; Abdellaoui, Bleichrodt and l'Haridon 2008).

${ }^{4}$ Under both RDU and PT, risk attitude is meant to depend on two components, namely attitude toward consequences (encapsulated in utility) and attitude toward probabilities (captured through probability weighting).
} 
domain. In particular, the comparison between the hypothetical and real conditions does not support the hypothetical bias. Besides, and more importantly perhaps, the subjects did not seem either to integrate prior gains with subsequent losses or to systematically play with house money when losses were "covered". Consequently, our data neither support the prospect-theory-with-memory effect nor replicate the house money effect. When combined, these findings suggest that the choice of a payment scheme may not be a very critical issue in the loss domain.

The second major finding of the study has a somewhat different flavor: in the gain domain, the subjects appeared to exhibit significantly more risk seeking and to produce noisier data when choices were hypothetical than when they were real, bringing support to the hypothetical bias. The overall conclusion is that, in the gain domain more than in the loss domain perhaps, the use of an incentive-compatible reward procedure should be considered.

The remainder of the paper is organized as follows. Section 2 describes the four hypotheses under investigation, while Section 3 presents the experimental design and Section 4 reports the results. Section 5 concludes.

\section{The Hypotheses under Investigation}

The aim of our experimental study was to answer three questions and test four hypotheses.

The first question is whether the losses-from-an-initial-endowment procedure may be considered as an acceptable proxy for real losses (since it is obviously easier to implement). To answer this question, we wished to test the following two assumptions A1.1. and A1.2.:

A1.1. (house money effect): When losses are covered, the subject may not consider them as real and she may "play with the house money" as if it were a manna. This 
may result in more risk seeking than when losses are real and, presumably, in a behavior similar to the one induced when losses are hypothetical.

To test A1.1., we needed to compare behavior in the covered losses treatment with behavior in the real losses treatment on the one hand, and behavior in the covered losses treatment with behavior in the hypothetical losses treatment on the other hand.

A1.2. (prospect-theory-with-memory effect): When losses are covered, the subject may translate losses into gains (by integrating the initial endowment into subsequent losses). This may result in less risk seeking than when losses are real (since gains tend to induce risk aversion while losses tend to induce risk seeking) and, presumably, in a behavior similar to the one induced under a real gains condition.

To test A1.2., we needed to compare behavior in the covered losses treatment with behavior in the real losses treatment on the one hand, and behavior in the covered losses treatment with behavior in the corresponding real gains treatment on the other hand. ${ }^{5}$

The second question is whether hypothetical losses may induce the same behavior as real losses or not. The potential problem with hypothetical losses is the hypothetical bias: if a subject does not consider hypothetical losses seriously, she may be tempted to take more risks than when she is likely to lose money from her own pocket. More fundamentally, the underlying question is whether the use of monetary incentives is necessary to elicit truthful responses in the loss domain, or whether hypothetical choices may be considered as an acceptable proxy for real losses (since they are obviously easier to implement).

To answer this question, we wished to test the following assumption A2.:

A2. (hypothetical bias in the loss domain): In the loss domain, the subject may tend to exhibit more risk seeking when choices are hypothetical than when they are real.

\footnotetext{
${ }^{5}$ This latter comparison could not be done directly. Actually, it was first necessary to recode "covered losses" as gains, by integrating the initial endowment into subsequent losses. The integration and recoding mechanism is described in Section 3 and Appendix B.
} 
To test A2., we needed to compare behavior in the real losses treatment with behavior in the hypothetical losses treatment.

The third question is whether hypothetical gains may induce the same behavior as real gains or not. If a subject does not consider hypothetical gains seriously, she may be tempted to take more risks than when she is likely to win for real.

To answer this question, we wished to test the following assumption A3.:

A3. (hypothetical bias in the gain domain): In the gain domain, the subject may tend to exhibit more risk seeking (or less risk aversion) when choices are hypothetical than when they are real.

To test A3., we needed to compare behavior in the real gains treatment with behavior in the hypothetical gains treatment.

Table 1 summarizes the four assumptions under investigation as well as the five payment conditions introduced to test them.

\section{INSERT TABLE 1 ABOUT HERE}

\section{Experimental Design and Stimuli}

To compare the subjects' behavior across the 5 payment schemes, we ran a paper-andpencil experiment involving three sessions scheduled at regular and spaced-out intervals, with at least 15 days between each session. In each session, the subjects had to fill out a questionnaire. The three questionnaires were strictly identical; only the payment condition differed. Subjects were informed before the study that there would be three sessions and that each session would involve choices between two (gain- or loss-) lotteries. They were told that, if they agreed to take part in the experiment, they had to take the commitment to participate in the three sessions. To enforce this commitment as well as to avoid carry-over and memory 
effects across sessions, the subjects did not receive any information as regards the specific incentive scheme associated with each session until they showed up for that session.

The first session was run under a hypothetical condition, involving both gain- and losschoice situations with no performance-based payment but a flat-fee. The second session was run under a real condition. It also included both gain- and loss- choice situations, and a random-lottery payment scheme was introduced over the whole set of tasks (see below for a description). Finally, the third session involved both hypothetical gains (as fillers, in order to make the three questionnaires strictly identical) and covered losses (using the losses-from-aninitial-endowment procedure) with a random-lottery payment scheme as in the second session.

The typical task consisted in choosing between a binary lottery and a sure amount. For a given lottery, the subject was asked to make a series of 21 choices between the lottery and different sure amounts, so that we could obtain her certainty equivalent for the lottery without asking her directly (see Appendix A for an example of a typical choice situation and its 21 choice tasks). Indeed, choice-based elicitation procedures have been shown to induce fewer inconsistencies and produce more reliable data than direct matching, which requires that the subject states her indifference point directly (Bostic, Herrnstein and Luce 1990). Choicebased elicitation procedures also allow the implementation of incentive-compatible payment schemes such as the Becker, DeGroot and Marschak (1964) procedure.

Now, each questionnaire contained 23 different choice situations (i.e., 23 different binary lotteries), that each included 11 loss situations and 11 gain situations built from the loss situations to allow the testing of Assumption A1.2., plus a special gain situation involving a higher potential gain to make the experiment more attractive. The mechanism through which each of the 11 gain lotteries was built from its loss counterpart is described in detail in Appendix B, but we now give its main features. As said in the introduction, the 
prospect-theory-with-memory effect implies that, in the covered losses condition, the subject integrates the initial endowment into subsequent losses, thus behaves as if she were facing the corresponding real gains condition. Testing the prospect-theory-with-memory effect thus required that, for each covered losses lottery, we built: (1) a "recoded" covered losses certainty equivalent: the initial endowment was simply added to the certainty equivalent obtained from the subject, allowing us to predict how the subject would have behaved when facing the corresponding gain lottery given her actual behavior in the loss domain, (2) a real gains condition in which (a) each gain lottery was built from a loss one by adding the initial endowment to each consequence (b) a random-lottery payment scheme was introduced. After that, the only thing to do was to compare the subject's recoded certainty equivalent in the "covered-losses-recoded-as-gains" condition with her certainty equivalent elicited in the real gains condition. Similar certainty equivalents (i.e. a similar level of risk aversion) would bring strong support to the prospect-theory-with-memory effect. By contrast, a lower level of risk aversion in the covered-losses-recoded-as-gains condition would be consistent with the house money effect.

A maximum "real" loss of 20 euro was introduced in our experimental design. Although 20 euro might be considered as a small amount of money, the pilot experiment showed that the prospect of losing 20 euro was salient enough to make it a matter of concern for our student subject pool. Given this maximum real loss of 20 euro, an initial endowment A of 20 euro was chosen for the covered session.

In the questionnaires, the gain- and loss- choice situations were presented in two separate parts, namely a "gain part" and a "loss part", which were clearly identified as such. To allow for the detection of any order effect, half of the subjects first answered the loss (resp. gain) questions in each of the three sessions. In addition, each gain/loss part of the questionnaire was divided into two subparts, which were also clearly identified as such in the 
folders. In the first subpart, called the "outcome subpart" in the following, the probabilities were held constant and six lotteries were built according to the following pattern: (X, 25\%; Y, $75 \%)$ in the loss domain and $(X+20,25 \%, Y+20,75 \%)$ in the gain domain, ${ }^{6}$ with $\mathrm{X}$ and $\mathrm{Y}$ taking different values such that $-20 \leq \mathrm{X}<\mathrm{Y} \leq 0$. Within each outcome subpart of the questionnaire, the order in which the six lotteries were presented was randomized to prevent any order effect.

In the second subpart, called the "probability subpart" in the following, the consequences were held constant and five lotteries were built according to the following pattern: $(-20, p ; 0,1-p)$ in the loss domain and $(0, p ; 20,1-p)$ in the gain domain, with $p$ taking five different values $(5 \%, 25 \%, 50 \%, 75 \%, 95 \%)$. The pilot sessions taught us that the subjects found it easier to deal with an increasing order in probabilities (from $\mathrm{p}=5 \%$ to $\mathrm{p}=95 \%$ ) than with a randomized order. ${ }^{7}$ Finally, note that, in the probability subpart of the gain part of the questionnaire, an additional special lottery $(60,5 \% ; 0 ; 95 \%)$ was introduced to make the experiment more attractive for the subjects.

Remember that our experimental design was meant to allow the investigation (resp. comparison) of both the subjects' risk attitude and components of risk attitude in (resp. across) the five payment conditions. Both the outcome and probability subparts allowed us to collect certainty equivalents, thus to investigate each subject's risk attitude. However, the outcome subpart was specifically designed to allow the estimation of the utility function at the individual level, while the probability subpart was intended to allow the elicitation of probability weights (at the individual level as well) for the five probabilities under consideration.

\footnotetext{
${ }^{6}$ According to the mechanism described above and in Appendix B.

${ }^{7}$ The main advantage of this strategy is that it prevents between-tasks violations of stochastic dominance; its main drawback is that it may induce potential order effects in the subjects' answers. Pilot sessions convinced us that the advantage was large enough to counterbalance the drawback.
} 
The stimuli are summarized in Table 2. Note that the loss [resp. gain] lottery (-20, 25\%; $0,75 \%)$ [resp. $(20,75 \% ; 0,25 \%)]$ was given twice in each questionnaire, in both the outcome and probability subparts. This provided us with a consistency test.

\section{INSERT TABLE 2 ABOUT HERE}

As mentioned previously, three sessions were organized for the filling out of the questionnaires. A within-subject design was adopted. The reason for this is threefold. First, within-subject designs allow much higher statistical power. Second, they necessitate a smaller pool of subjects, which is an obvious advantage when real losses are at stake. Third, betweensubject designs may lead to strong inconsistencies in judgments (Birnbaum 1999). Obviously, within-subject designs may induce unwanted carry-over and memory effects across sessions, as well as undesirable financial strategies from the subjects (trying to make up for their previous losses, for instance). This is why: (1) the subjects were presented the three conditions at different points of time (as suggested by Keren and Raaijmakers 1988) and we arranged for intervals of at least 15 days between each session, (2) the sessions were run in the same order for all the subjects, (3) the order in which the three (hypothetical, real, covered) sessions were held was chosen to minimize carry-over effects. Indeed, running the real session before the hypothetical one could have enhanced the hypothetical bias. Moreover, running the covered session before the real one could have induced an undesirable prospecttheory-with-memory effect: those subjects who had won money in the covered session could have been tempted to integrate these gains into subsequent real losses. ${ }^{8}$

\footnotetext{
${ }^{8}$ Naturally, running the real session before the covered one as we did could have also affected behaviour in the covered session. In particular, those subjects who incurred a loss in the real session could have been tempted to try to make up for this loss in the covered session. Actually, we found no significant difference in behaviour in the covered session between those 17 subjects who experienced a loss in the real session and those 29 subjects (including 9 subjects with a zero gain) who experienced a gain. Risk attitudes in the covered session were also regressed on real payments to study whether subjects took gains and losses from the second session into account in the last session tasks. For both gains and losses, the regression coefficients associated with these payments were never significantly different from zero.
} 
The main features of the experimental design were calibrated to make the experiment both ethically acceptable and suitable for our purpose. ${ }^{9} 46$ subjects participated in the final experiment. All of them were either undergraduate or graduate students, most of them in economics, but none of them was familiar with decision theory. All the subjects were volunteers. Students were contacted by e-mail, and informed about the most important aspects of the experiment, namely the fact that: (1) the study would involve three sessions, (2) they could undergo a maximum loss of 20 euro from their own pocket at the end of the study, (3) they could also win some money, with a maximum potential gain of 80 euro over the whole experiment, (4) the probability of gain was higher than the probability of loss. As said before, the subjects were not informed about the specific nature of each session before they arrived; the aim was both to avoid that they carry out undesirable strategies across the sessions and to minimize the "sample selection" bias. ${ }^{10}$

In each session, the subjects were gathered together in small groups (from 2 to 7 subjects) and asked to sit down in a classroom to fill out their folder. Before they completed the questionnaire, the subjects were given some oral instructions, and informed of the payment condition that would be implemented after the session. At the beginning of the first session, they were told that they would be given a 3 euro flat-fee payment at the end of the session. At the beginning of the second session, they were told that, at the end of the session, each subject would be asked to select a single choice task at random from among both the gain and loss situations, and would have to play it out for real. ${ }^{11}$ At the beginning of the third

\footnotetext{
${ }^{9}$ For instance, the expected reward for the entire experiment was about 17 euro. The expected loss in the second session was about 3.8 euro, but it was counterbalanced by an expected gain of about 5.8 euro (the expected reward was thus about 2 euro). For the 17 subjects who actually lost some real money at the end of the second session, the average loss was about 8 euro ( 2 subjects incurred the maximum possible loss of 20 euro). At the end of the whole experiment, only 2 subjects actually lost some money from their own pocket (less than 5 euro).

${ }^{10}$ Similarly, the subjects were not told anything about the future use of the money they might lose, except that we would not put it in our pocket. At the end of the experiment, the subjects who had lost some money were asked to choose a charity to which we could send their money.

${ }^{11}$ To be more specific, the subjects were told that a single choice situation (i.e. a table as in Appendix A) would be selected at random first, and that a single choice task (i.e. a line in the selected table) would then be selected at random and played out for real.
} 
session, they were given a 20 euro bill and asked to put it in their pocket. ${ }^{12}$ Then they were told that, at the end of the session, each subject would be asked to select a single choice task at random from among the loss situations, and would have to play it out for real. ${ }^{11}$ They were also told that the highest potential loss was 20 euro, so that they could not lose any money from their own pocket. It was essential that the subjects be perfectly aware that they could not lose their own money so that we could properly investigate whether they considered these covered losses either as real losses, as real gains (as suggested by the prospect-theory-withmemory effect) or as house money.

After the subjects as a group were given the instructions regarding the payment procedure, they were asked to answer a set of five practice questions included in the questionnaire and to call upon us if they had any questions. They were then requested to fill out the questionnaire at their own pace. In each session, the payment procedure was implemented individually for each subject in another room, just after she filled out the questionnaire. Overall, each session lasted about 30 minutes, including the instructions set and the implementation of the payment procedure.

The voluntary nature of the recruitment, as well as the possibility that some of the subjects might lose money from their own pocket, could have been responsible for a strong selection bias toward risk seeking among the group. However, our results (see below, Section 4) show a level of risk aversion that is consistent with that found in previous similar studies (e.g. Tversky and Kahneman 1992; Abdellaoui 2000; Stott 2006). This suggests that our experimental design rather succeeded in counterbalancing loss aversion and making the experiment attractive, even for risk avoiders.

\footnotetext{
${ }^{12}$ Note that we chose to provide the subjects with the initial endowment at the beginning of the session. Giving it some time (a few days or weeks) before the experiment, as in Bosch-Domenech and Silvestre (2010) for instance, would have certainly been more appropriate, since our strategy could be suspected of enhancing the prospect-theory-with-memory effect. But our idea was to introduce a simple payment scheme that could be easily replicated and used in any experiment involving losses. The problem with more sophisticated strategies is that they may induce the subjects to quit between the time they are given the endowment and the experimental session itself. Moreover, if no prospect-theory-with-memory effect arose with our basic procedure, one could reasonably expect that no such effect would occur when using a more sophisticated one.
} 


\section{Results}

\subsection{Consistency}

As mentioned before, the subjects were presented the loss [resp. gain] prospect $(-20$, $25 \% ; 0 ; 75 \%)$ [resp. $(20 ; 75 \% ; 0,25 \%)]$ twice in each questionnaire: first in the outcome subpart, second in the probability subpart of the corresponding loss [resp. gain] part. This provided us with 3 [resp. 2] consistency tests in the loss [resp. gain] domain (one for each payment condition).

Our data suggest that consistency was actually good. Paired $t$-tests show no significant difference within each pair of certainty equivalents, and Pearson correlations between answers are high (hypothetical losses, p-value: 0.75, Pearson's $\rho: 0.51$; real losses, p-value: 0.1, $\rho$ : 0.39; covered losses, p-value: $0.73, \rho: 0.47$; hypothetical gains, $p$-value: $0.34, \rho: 0.73$; real gains, p-value: 0.26, $\rho: 0.67)$. Moreover, no significant difference in consistency arose between the treatments, either for losses (p-value: 0.29) or for gains ( $p$-value: 0.87$)$.

\subsection{Risk Attitude and the Outcome Subpart of the Questionnaires}

We now present the results obtained from the outcome subpart of the questionnaires. Being highly similar, the results obtained from the probability subpart will not be presented here, unless otherwise stated in the text (they are available upon request). Following the same structure as Table 1 for a straight reading, Table 3 shows an overview of the results. Table 3 suggests that treatment did not affect behavior in the loss domain, while it did in the gain domain. Now, we discuss the results more thoroughly.

INSERT TABLE 3 ABOUT HERE 


\section{Testing Assumption A1.1: the House Money Effect}

Table 4 shows the median certainty equivalents as well as the interquartile ranges obtained in the outcome subpart of the loss part of the questionnaires, under the three (hypothetical, real and covered) loss payment conditions. Results are provided in absolute values.

The data show that a majority of subjects were risk averse. Insofar as the probability of the worst outcome in the outcome subpart of the questionnaire was always equal to $25 \%$, this result is consistent with previous empirical evidence showing that risk aversion tends to prevail when the probability of the highest loss is low (see Tversky and Kahneman 1992 for instance).

\section{INSERT TABLE 4 ABOUT HERE}

The factorial ANOVA analysis performed over the three loss treatments shows that the risk premia obtained in the covered losses treatment are very close to the ones obtained in both the hypothetical and real losses treatments ( $p$-value: 0.29$)$. We found no significant difference due to either gender ( $p$-value: 0.50$)$, lottery order ( $p$-value: 0.14$)$ or gain/loss order ( $p$-value: 0.37 ). More specifically, a closer look at certainty equivalents in Table 4 shows that the subjects tended to be slightly more risk seeking when facing covered losses rather than real losses. This suggests that they did not fully consider covered losses as real. Covered losses therefore appear to be intermediate: they do not seem to raise a strong house money effect, but they do not really mimic real losses either. Conversely, the fact that the subjects tended to be slightly more risk averse when facing covered losses rather than hypothetical losses suggests that they did not consider the initial endowment as basic house money. However, the differences between hypothetical and covered losses never reach significance, except for lottery $(-15,25 \% ;-10,75 \%)$ (one-tailed Wilcoxon test, p-value: 0.01$)$. Finally, our data give little support to Assumption A1.1. (house money effect). 


\section{Testing Assumption A1.2: the Prospect-Theory-with-Memory Effect}

The question remains whether the losses-from-an-initial-endowment procedure induced the subjects to consider covered losses as gains as suggested by the prospect-theory-withmemory effect. If so, they should have exhibited more risk aversion than in the real losses condition. They also should have exhibited a behavior similar to that observed in the real gains condition.

As previously stated, the subjects tended to be slightly more risk seeking when faced with covered losses than with real losses, which contradicts the prospect-theory-with-memory effect. In addition, our data provide clear evidence against the possibility that the subjects recoded covered losses as gains (by integrating the initial endowment into subsequent losses). First, a factorial ANOVA shows that recoded covered losses induced a significantly different behavior as compared to both hypothetical ( $p$-value: 0.002$)$ and real gains ( $p$-value: 0.000$)$. Second, the comparison between hypothetical gains and recoded covered losses using Wilcoxon two-tailed tests shows that for only two lotteries (out of six) were certainty equivalents not significantly different $[(10,25 \% ; 20,75 \%), p$-value: $0.16 ;(0,25 \% ; 20,75 \%)$, p-value: 0.78]. Moreover, comparison between real gains and recoded covered losses using Wilcoxon two-tailed tests shows that for only one lottery out of six were certainty equivalents not significantly different $[(0,25 \% ; 5,75 \%), p$-value: 0.88$]$. Consequently, our data allow us to reject Assumption A1.2. (prospect-theory-with-memory effect).

\section{Testing Assumption A2: the Hypothetical Bias for Losses}

First, a repeated factor ANOVA on risk premia suggests that there is no systematic difference between the hypothetical and real losses payment schemes ( $p$-value: 0.25$)$.

Now, based on medians, hypothetical losses tend to induce more risk seeking than real losses for four lotteries out of six (see Table 4). But differences between hypothetical and real 
losses as regards risk aversion never reach significance (at 5\%), except for Lottery (-20, 25\%; 0,75\%) (one-tailed Wilcoxon test; p-value: 0.045 ). This lottery has three specificities that may explain its special status. First, the worst consequence is also the highest loss the subject could incur during the experiment. Second, the spread between consequences is the largest one. Third, the best consequence corresponds to the status quo. Considering that the level of risk aversion may increase with the size of stakes under the real payoff condition, but not under the hypothetical condition (as shown by Holt and Laury 2002 in the gain domain), Lottery $(-20,25 \% ; 0,75 \%)$ may have induced an unusually high level of risk aversion when losses were real, but not when they were hypothetical. ${ }^{13}$ This latter result brings some support to that kind of hypothetical bias identified by Schoemaker (1990) on very similar lotteries. However, it does not generalize on our data (with more standard lotteries). Moreover, even though interquartile ranges suggest that the dispersion of the results is lower in the real treatment than in the hypothetical one, this difference is never significant (according to a Levene's test on variances equality: all p-values are higher than 0.05). Consequently, our data allow us to reject Assumption A2. (the hypothetical bias in the loss domain).

\section{Testing Assumption A3: the Hypothetical Bias for Gains}

At this stage, it may be of interest to investigate whether the previous result also applies when comparing the hypothetical and real gains treatments.

A factorial ANOVA shows that risk aversion is stronger when gains are real ( $p$-value: 0.01). We found no significant difference due to either gender ( $p$-value: 0.60 ) or lottery order (p-value: 0.40$)$. Gain/loss order was marginally significant ( $p$-value: 0.06$)$, which is consistent with previous literature in the gain domain (see Harrison et al. 2005).

\footnotetext{
${ }^{13}$ This does not hold if Holt and Laury’s findings reflect for losses.
} 
Table 5 shows the median certainty equivalents, as well as the interquartile ranges, obtained in the outcome subpart of the gain part of the questionnaires, under both the hypothetical gains and real gains conditions. Results are given in absolute values. In accordance with the usual pattern of risk aversion observed when high probability-high gain prospects are involved (remember that, in our design, the probability of the highest gain is equal to $75 \%$ ), our data offer strong evidence of risk aversion in both treatments: 11 (out of 12) median certainty equivalents are lower than the corresponding expected values.

Data from Table 5 also show that, most of the time, risk aversion is slightly stronger when gains are real. One-tailed Wilcoxon tests show that the difference between certainty equivalents is significant for 2 lotteries out of $6[(0,25 \% ; 20,75 \%), p$-value: $0.02 ;(5,25 \%$; 15, 75\%), p-value: 0.045$]$ and marginally significant for two other ones [(10, 25\%; $20,75 \%)$, p-value: $0.055 ;(0,25 \% ; 5,75 \%), p$-value: 0.06$].{ }^{14}$ Consequently, our data bring some support to Assumption A3. (the hypothetical bias in the gain domain).

\section{INSERT TABLE 5 ABOUT HERE}

\subsection{The Components of Risk Attitude: Utility and Probability Weighting}

In order to get some deeper information about our subjects' risk attitude in each treatment, the utility and probability weighting functions were elicited using the semiparametric method developed in Abdellaoui, Bleichrodt and l'Haridon (2008). Since this method was initially designed for the elicitation of indifferences, it was adapted to be compatible with the multiple price list format used in this experiment, thus with a series of

\footnotetext{
${ }^{14}$ Lottery $(0,25 \% ; 20,75 \%)$ offers the same specificities as the one that induced a specific behavior in the loss domain (it offers both the worst and best possible consequences as well as, consequently, the largest spread between consequences). The conditions under which Holt and Laury (2002)'s above-mentioned result is likely to apply are thus satisfied. However, the other three lotteries do not share these peculiarities, so they are outside Holt and Laury's framework.
} 
discrete choices. To be more specific, a one-parameter power specification was assumed for the utility function $\mathrm{u}$, with $\mathrm{u}(\mathrm{x})=\mathrm{x}^{\alpha}$. Then, a structural maximum likelihood model was estimated using the 6 outcome subpart certainty equivalent questions, assuming rankdependent utility/prospect theory preferences as well as a Fechner error specification (see Harrison and Rutström 2008, section 3.1 for more details about structural models; Abdellaoui et al. 2010 for a similar treatment). In the loss [resp. gain] domain, both utility parameter $\alpha$ and probability weight $\mathrm{w}^{-}(0.25)$ [resp. $\left.\mathrm{w}^{+}(0.75)\right]$ were thus estimated. Once utility was estimated, five decision probability weights were elicited non-parametrically for each subject on the basis of the 5 probability subpart questions, using the previously estimated value of parameter $\alpha$. Aggregate results for utility (and probability weights $\mathrm{w}^{-}(0.25)$ and $\mathrm{w}^{+}(0.75)$ ) are given in Table $6 .^{15}$

\section{INSERT TABLE 6 ABOUT HERE}

Based on $95 \%$ confidence intervals given in Table 6 , comparison of utility parameters $\alpha$ across the three loss treatments shows no significant difference between the hypothetical and covered losses treatments, as well as between the covered and real losses treatments. However, the utility function appears to be significantly more concave in the hypothetical and covered losses treatments than in the real losses one. To be more specific, utility was found to be convex in the real losses treatment, but convexity did actually not reach significance, meaning that linearity could not be rejected. On the other hand, the slight pattern of concavity observed for both hypothetical and covered losses is neither unusual in the literature (Abdellaoui, Bleichrodt and l'Haridon 2008; Bruhin, Fehr-Duda and Epper 2010) nor

\footnotetext{
${ }^{15}$ Note that we did not intend to estimate the entire prospect theory model here. As we did not collect any information about the subjects' behavior when faced with mixed prospects, we could not make any inference about loss aversion in our experiment. As a result, our estimations were restricted to either gains or losses.
} 
incompatible with rank-dependent theories such as Prospect Theory (Chateauneuf and Cohen 1994).

It was previously established that attitude toward risk did not significantly differ between the hypothetical and real treatments in the loss domain (suggesting the absence of any hypothetical bias). Though apparently contradictory, the significant difference in terms of utility curvature between the hypothetical and real losses treatments may actually be reconciled with that previous finding. It simply demonstrates that the overall no-effect of treatment on risk attitude observed in the loss domain is actually driven by two counterbalancing effects: on utility on the one hand, and on probabilistic risk attitude on the other hand, as will be shown below.

As regards noise, the estimated error parameters are similar across treatments in the loss domain, except that they are slightly higher for the covered condition. Likewise, the standard errors are similar between the treatments.

Now, in the gain domain, no significant difference arises between the real and hypothetical conditions, regarding either (concave) utility or error.

As regards probability weighting, five probability weights were elicited non parametrically in each domain on the basis of the 5 probability-subpart certainty equivalent questions, thus for $\mathrm{p}=5 \%, 25 \%, 50 \%, 75 \%$, and $95 \%$. The median probability weights and their corresponding interquartile ranges are given in Table 7.

\section{INSERT TABLE 7 ABOUT HERE}

Once the 5 probability weights were elicited, the probability weighting function $w(p)$ was determined by maximum likelihood estimation, assuming a Goldstein and Einhorn (1987) linear-in-odds two-parameter specification, with $\mathrm{w}(\mathrm{p})=\delta \mathrm{p}^{\gamma} /\left(\delta \mathrm{p}^{\gamma}+(1-\mathrm{p})^{\gamma}\right)$. In this parametric 
form, $\delta$ controls for elevation and reflects the extent to which people are attracted to probabilistic risk, while $\gamma$ governs curvature (i.e. sensitivity to probabilities, see Abdellaoui, l'Haridon and Zank, 2010 for more details on these concepts). The results are shown on Figure 1 for losses, and on Figure 2 for gains.

\section{INSERT FIGURE 1 ABOUT HERE}

Based on $95 \%$ confidence intervals, comparison of parameters $\delta$ across the three loss treatments shows no significant difference in elevation between real, covered and hypothetical losses. This result suggests that the degree of reality of losses at stake may not affect attitude toward probabilistic risk. By contrast, curvature (thus sensitivity to probabilities) appeared to be significantly lower in the real losses condition than in both the covered and hypothetical losses conditions. This might contradict the usual claim that real choices should help cognitive effort (which may in turn enhance sensitivity to probability).

\section{INSERT FIGURE 2 ABOUT HERE}

In the gain domain, we found a significant difference between the real and hypothetical gains conditions for both elevation and curvature. First, as in the loss domain and quite counter-intuitively, the real condition seemed to dampen sensitivity to probabilities. Second, probabilistic risk seemed to be less attractive for real prospects than for their hypothetical counterpart. In other words, real gains might induce more pessimism than hypothetical gains, which may in turn explain why risk aversion was more prevalent when gains were real than hypothetical (in accordance with the hypothetical bias). 


\section{Discussion}

A large body of experimental literature has been devoted to the twofold question of whether monetary incentives are actually necessary or not to collect high-quality experimental data, and, if they may not, which reward scheme it is possible/preferable to use. Up to now, no clear-cut or general conclusion has been drawn from these studies. However, economists tend to consider that no appropriate behavior can be expected from the subjects unless a performance-based payment scheme is introduced in the experimental design.

When there are losses at stake, monetary incentives are obviously hard to implement: it is quite difficult, for ethical as well as for practical reasons, to make the subjects lose for real by introducing a real losses payment condition (with subjects incurring some loss from their own pocket). Consequently, it would be of great interest if some easier-to-implement reward schemes could do as good a job as a real losses condition. In our experimental design, the idea was to introduce a real losses condition that could be used as a benchmark to assess the efficiency of two alternative payment schemes, namely a hypothetical losses condition, based on a flat-fee payment, and a covered losses condition (or losses-from-an-initial-endowment procedure), allowing the subjects to lose money from an initial endowment, but not from their own pocket.

In the loss domain, our data suggest that few differences exist as regards behavior between the three reward schemes under consideration. The only significant difference we found was in utility between the real and hypothetical losses treatments. Consequently, neither the losses-from-an-initial-endowment procedure nor the hypothetical losses procedure seem to suffer from any expected bias. The losses-from-an-initial-endowment procedure exhibits three features that make it a good candidate as a payment scheme in the loss domain. First, we found no evidence for a prospect-theory-with-memory effect and only slight 
evidence for a house money effect: as compared to the real losses treatment, the use of a losses-from-an-initial-endowment procedure did not seem to strongly bias behavior, either toward more risk seeking or toward more risk aversion. Second, the components of risk attitude, utility and probability weighting, were highly similar in both the real and covered treatments. Third, as compared to either real losses or hypothetical losses, covered losses produced only a slightly higher amount of noise. Taken together, these findings suggest that the losses-from-an-initial-endowment procedure, which has been widely used as a proxy to real losses, can be considered as such and used with a high level of confidence in future incentivized experiments involving losses.

It is of interest to observe that our data do not replicate the house money effect, which has been well documented in the literature. A crucial difference between the seminal experimental studies conducted by Thaler and Johnson (1990) and Battalio, Kagel and Jiranyakul (1990) (see also Keasey and Moon, 1996) and ours is the sign of the prospects involved in the experimental design. In Thaler and Johnson (1990)'s study for instance, the subjects had to choose between the status-quo and a 50/50 mixed prospect; in our study, the subjects had to choose between a sure loss and a prospect involving losses only. In the former study, "after a gain, subsequent losses that are smaller than the original gain can be integrated with the prior gain, mitigating the influence of loss aversion and facilitating risk-seeking" (Thaler and Johnson, 1990, p. 657). By contrast, loss aversion played no role in our experiment, which may have limited the increase in risk seeking expected from the house money effect.

More boldly perhaps, our results also suggest that hypothetical losses could be considered as an acceptable proxy for real losses. This could greatly facilitate the task of 
experimentalists seeking to examine behavior under risk (and its components) in the loss domain, particularly when they are limited by financial constraints. ${ }^{16}$

In the gain domain, our results look somewhat different. Indeed, hypothetical gains appeared to induce more risk seeking among our subjects than real gains. In addition, as compared to real ones, hypothetical choices were found to produce a larger amount of noise as well as a more optimistic/positive attitude toward probability. Taken together, these findings bring some support to the hypothetical bias hypothesis. Even though this support is not very strong, it suggests that a real payment condition should be used in the gain domain.

At this stage, it is worth wondering why the impact of monetary incentives seems to depend on the domain under consideration. It may be the case that the subjects make a strong difference between a situation in which they hope to win real money and a situation in which they know there is no real stake, while the prospect of losing something - be it real money, covered or hypothetical money - is sufficiently salient and unpleasant to make the subjects considering it as equally realistic, in a certain manner.

Of course, the initial caveat still stands: we do not claim that our results could be directly extended outside the experimental conditions under which they were obtained (kind of task, level of losses). In particular, it may be the case that behavior in interactive settings involving losses, or even behavior in individual decision making settings as far as large losses are involved, more strongly depends on the payment scheme.

\footnotetext{
${ }^{16}$ In particular, the losses-from-an-initial-endowment procedure may induce a large cost if the subjects happen not to lose much money from the endowment.
} 


\section{References}

Abdellaoui, M. (2000). Parameter-free elicitation of utilities and probability weighting functions. Management Science, 46, 1497-1512.

Abdellaoui, M., Baillon, A., Placido, L., Wakker P.P. (2010). The rich domain of uncertainty. American Economic Review, forthcoming.

Abdellaoui, M., Bleichrodt, H. Paraschiv, C. (2007). Measuring loss aversion under prospect theory: a parameter-free approach. Management Science, 53, 1659-1674.

Abdellaoui, M., Bleichrodt, H., l'Haridon, O. (2008). A tractable method to measure utility and loss aversion in prospect theory. Journal of Risk and Uncertainty, 36, 245-266.

Abdellaoui, M., l'Haridon, O., Zank, H. (2010). Separating curvature and elevation: a parametric weighting function. Journal of Risk and Uncertainty, 41, 39-65.

Arkes H. R., Blumer C. (1985). The psychology of sunk costs. Organizational Behavior and Human Decision Processes, 35, 124-140.

Arkes H. R., Herren L. T., Isen A. M. (1988). The role of potential loss in the influence of affect on risk-taking behavior. Organizational Behavior and Human Decision Processes, 42, 181-193.

Baltussen, G., Post, T., van den Assem, M. Wakker, P. (2008). The effects of random lottery incentive schemes: Evidence from a dynamic risky choice experiment. Working Paper Erasmus University Rotterdam.

Bardsley N. (2000) Control without deception: Individual behaviour in free-riding experiments revisited. Experimental Economics, 3, 215-240.

Battalio, R. C., Kagel J., and Jiranyakul, K. (1990). Testing between alternative models of choice under uncertainty: Some initial results. Journal of Risk and Uncertainty, 3(1), $25-50$.

Beattie J., Loomes G. (1997). The impact of incentives upon risky choice experiments. Journal of Risk and Uncertainty, 14, 155-168.

Becker, G. M., DeGroot, M. H., Marschak, J. (1964). Measuring utility by a single-response sequential method. Behavioral Science, 9, 226-232.

Birnbaum, M. H. (1999). How to show that $9>221$ : Collect judgments in a between-subjects design. Psychological Methods, 4(3), 243-249.

Bosch-Domenech A., Silvestre J. (2010). Averting risk in the face of large losses; Bernoulli vs. Tversky and Kahneman. Economics Letters, 107(2), 180-182.

Bostic R., Herrnstein R. J., Luce R. D. (1990). The effect on the preference reversal phenomenon of using choice indifferences. Journal of Economic Behavior and Organization, 13, 193-212.

Bruhin, A., Fehr-Duda, H., Epper, T. (2010). Risk and rationality: Uncovering heterogeneity in probability distortion. Econometrica, 78(4), 1375-1412.

Camerer, C. F., Hogarth, R. M. (1999). The effects of financial incentives in experiments: A review and capital-labor-production framework. Journal of Risk and Uncertainty, 19(1), $7-42$.

Chateauneuf, A., Cohen, M. (1994). Risk seeking with diminishing marginal utility in a nonexpected utility model. Journal of Risk and Uncertainty, 9, 77-91.

Clark J. (2002). House money effects in public good experiments. Experimental Economics, $5(3), 223-231$.

Cox J. C., Grether D. M. (1996). The preference reversal phenomenon: Response mode, markets and incentives. Economic Theory, 7(3), 381-405.

Cubitt R. P., Starmer C., Sugden R. (1998). On the validity of the random lottery incentive system. Experimental Economics, 1, 115-131. 
Davis D. D., Holt C. A. (1993). Experimental Economics. Princeton, NJ: Princeton University Press.

Etchart-Vincent N. (2004). Is probability weighting sensitive to the magnitude of consequences? An experimental investigation on losses. Journal of Risk and Uncertainty, 28(3), 217-235.

Etchart-Vincent N. (2009). Probability weighting and the 'level' and 'spacing' of outcomes: An experimental study over losses. Journal of Risk and Uncertainty, 39(1), 45-63.

Fennema, H., van Assen, M. (1999). Measuring the utility of losses by means of the trade-off method. Journal of Risk and Uncertainty, 17, 277-295.

Gärling T., Romanus J. (1997). Integration and segregation of prior outcomes in risky decisions. Scandinavian Journal of Psychology, 38(4), 289-296.

Gibbons R. (1997). Incentives and careers in organizations. In D. Kreps and K. Wallis (Eds.), Advances in economic theory and econometrics, vol. II, Cambridge, England: Cambridge University Press.

Goldstein, W., Einhorn, H. (1987). Expression theory and the preference reversal Phenomena. Psychological Review, 94, 236-254.

Harrison G. W. (1994). Expected utility theory and the experimentalists. Empirical Economics, 19, 223-253.

Harrison G. W. (2006). Hypothetical bias over uncertain outcomes. In J. A. List (Ed.), Using experimental methods in environmental and resource economics, Northampton, MA: Elgar.

Harrison G. W. (2007). House money effects in public good experiments: Comment. Experimental Economics, 10(4), 429-437.

Harrison G. W., Johnson E., McInnes M. M., Rutström E. E. (2005). Risk aversion and incentive effects: Comment. American Economic Review, 95(3), 897-901.

Harrison G. W., Rutström E. E. (2008). Risk aversion in the laboratory. In N.Cox and G.W. Harrison (Eds.), Risk aversion in experiments, Research in Experimental Economics, 12, Bingley, UK: Emerald.

Hertwig R., Ortmann A. (2001). Experimental practices in economics: A methodological challenge for psychologists?. Behavioral and Brain Sciences, 24, 383-451.

Hertwig R., Ortmann A. (2002). Economists' and psychologists' experimental practices: How they differ, Why they differ, and how they could converge. In I. Brocas and J. D. Carillo (Eds.), The psychology of economic decisions. New York: Oxford University Press.

Holt C. A., Laury S. K. (2002). Risk aversion and incentive effects. American Economic Review, 92, 1644-1655.

Holt, C. (1986). Preference reversals and the independance axiom. American Economic Review, 76,508-515.

Isen A. M., Patrick R. (1983). The effect of positive feelings and risk taking: When the chips are down. Organizational Behavior and Human Performance, 31, 194-202.

Kahneman D., Tversky A. (1979). Prospect theory: An analysis of decision under risk. Econometrica, 47, 263-291.

Keasy K., Moon P. (1996). Gambling with the house money in capital expenditure decisions: An Experimental Analysis. Economics Letters, 50, 105-110.

Keren, G., Raaijmakers, J. (1988). On between-Subjects versus within-Subjects comparisons in testing utility theory. Organizational Behavior and Human Decision Process, 41, 233247.

Lazear E. (2000). Performance, pay and productivity. American Economic Review, 90(5), $1346-1361$.

Lee, J. (2008). The effect of the background risk in a simple chance improving model. Journal of Risk and Uncertainty, 36, 19-41. 
Mason C. F., Shogren J. F., Settle C, List J. A. (2005) Investigating risky choices over losses using experimental data. Journal of Risk and Uncertainty, 31(2), 187-215.

Read D. (2005). Monetary incentives, what are they good for? Journal of Economic Methodology, 12(2), 265-276.

Romanus J., Hassing L., Gärling T. (1996). A loss-sensitivity explanation of integration of prior outcomes in risky decisions. Acta Psychologica, 93, 173-183.

Schoemaker, P. (1990). Are risk-attitudes related across domains and response modes?. Management science, 36, 1451-1463.

Smith V. L. (1976). Experimental economics induced value theory. American Economic Review, 66, 274-279.

Smith V. L., Levin I. P. (1996). Need for cognition and choice framing effects. Journal of Behavioral Decision Making, 9, 283-290.

Starmer C., Sugden R. (1991). Does the random-lottery incentive system elicit true preferences? An experimental investigation. American Economic Review, 81(4), 971978.

Stott, H. P. (2006). Cumulative prospect theory's functional menagerie. Journal of Risk and Uncertainty, 32, 101-130.

Thaler R. H., Johnson E. J. (1990). Gambling with the house money and trying to break even: The effects of prior outcomes on risky choice. Management Science, 36(6), 643-660.

Tversky A., Kahneman D. (1992). Advances in prospect theory: Cumulative representation of uncertainty. Journal of Risk and Uncertainty, 5, 297-323.

Weber M., Zuchel H. (2001). How do prior outcomes affect risk attitude? Comparing escalation of commitment and the house-money effect. Decision Analysis, 2(1), 30-43. 
Table 1: The Five Payment Conditions and the Four Tested Assumptions.

\begin{tabular}{|c|c|c|c|}
\hline & Нypo. losses & Real losses & Real gains \\
\hline $\begin{array}{c}\text { Covered } \\
\text { losses }\end{array}$ & $\begin{array}{l}\text { House money effect } \\
\text { (A1.1.) }\end{array}$ & $\begin{array}{l}\text { House money effect } \\
\text { (A1.1.) } \\
\text { Prospect-theory-with- } \\
\text { memory effect } \\
\text { (A1.2.) }\end{array}$ & $\begin{array}{l}\text { Prospect-theory-with- } \\
\text { memory effect and } \\
\text { recoding } \\
\left(\mathrm{A} 1.2^{\mathrm{a}}\right)\end{array}$ \\
\hline $\begin{array}{l}\text { Hypo. } \\
\text { losses }\end{array}$ & & $\begin{array}{l}\text { Hypothetical bias for } \\
\text { losses } \\
\text { (A2.) }\end{array}$ & \\
\hline $\begin{array}{c}\text { Hypo. } \\
\text { gains }\end{array}$ & & & $\begin{array}{l}\text { Hypothetical bias } \\
\text { for gains } \\
\text { (A3.) }\end{array}$ \\
\hline
\end{tabular}

Hypo.: Hypothetical

a: Comparison between real gains and "recoded" covered losses 
Table 2: The Stimuli.

\begin{tabular}{|c|c|c|}
\hline & Loss part & Gain part \\
\hline $\begin{array}{l}\text { Outcome } \\
\text { subpart }^{\mathrm{a}}\end{array}$ & $\begin{array}{c}(-20, p ; 0,1-p) \\
(-10, p ; 0,1-p) \\
(-5, p ; 0,1-p) \\
(-10, p ;-5,1-p) \\
(-20, p ;-15,1-p) \\
(-15, p ;-5,1-p) \\
\text { with } p=25 \%\end{array}$ & $\begin{array}{c}(20,1-\mathrm{p} ; 0, \mathrm{p}) \\
(20,1-\mathrm{p} ; 10, \mathrm{p}) \\
(20,1-\mathrm{p} ; 15, \mathrm{p}) \\
(15,1-\mathrm{p} ; 10, \mathrm{p}) \\
(5,1-\mathrm{p} ; 0, \mathrm{p}) \\
(15,1-\mathrm{p} ; 5, \mathrm{p}) \\
\text { with } 1-\mathrm{p}=75 \%\end{array}$ \\
\hline $\begin{array}{l}\text { Probability } \\
\text { subpart }^{\text {b }}\end{array}$ & $\begin{array}{c}(-20, \mathrm{p} ; 0,1-\mathrm{p}) \\
\text { with } \mathrm{p}=5 \%, 25 \%, 50 \%, 75 \%, 95 \%\end{array}$ & $\begin{array}{c}(20,1-\mathrm{p} ; 0, \mathrm{p}) \\
\text { with } 1-\mathrm{p}=5 \%, 25 \%, 50 \%, 75 \%, 95 \% \\
+ \text { Additional lottery }(60,5 \% ; 0,95 \%)\end{array}$ \\
\hline
\end{tabular}

${ }^{\mathrm{a}}$ : The probabilities are held constant in the prospects, only the outcomes vary.

b. The outcomes are held constant in the prospects, only the probabilities vary. 
Table 3: Equality of Risk Premia Between Treatments (ANOVA tests).

\begin{tabular}{|c|c|c|c|}
\hline & Hypo. Losses & Real losses & Real gains \\
\hline $\begin{array}{c}\text { Covered } \\
\text { losses }\end{array}$ & $\begin{array}{l}\text { House money effect (A1.1.) } \\
\text { Equality of risk premia not } \\
\text { rejected ( } \mathrm{p}=0.66)\end{array}$ & $\begin{array}{l}\text { House money effect (A1.1.) } \\
\qquad \& \\
\text { Prospect-Theory-with- } \\
\text { memory effect (A1.2.) } \\
\text { Equality of risk premia not } \\
\text { rejected }(\mathrm{p}=0.25)\end{array}$ & $\begin{array}{l}\text { Prospect-theory-with- } \\
\text { memory effect and recoding } \\
\qquad\left(\mathrm{A} 1.2^{\mathrm{a}}\right) \\
\text { Equality of risk premia } \\
\text { rejected }\left(\mathrm{p}=0.002^{\mathrm{a}}\right)\end{array}$ \\
\hline $\begin{array}{l}\text { Hypo. } \\
\text { losses }\end{array}$ & & $\begin{array}{c}\text { Hypothetical bias } \\
\text { for losses (A2.) } \\
\text { Equality of risk premia not } \\
\text { rejected }(\mathrm{p}=0.25)\end{array}$ & \\
\hline $\begin{array}{l}\text { Hypo. } \\
\text { gains }\end{array}$ & & & $\begin{array}{l}\text { Hypothetical bias } \\
\text { for gains (A3.) } \\
\text { Equality of risk premia } \\
\text { rejected }(\mathrm{p}=0.01)\end{array}$ \\
\hline
\end{tabular}

Factorial repeated measures ANOVA on risk premia with three between-subject factors (gender, lottery order and gain/loss order) and two within-subject factors (lottery, session). The risk premium is defined as the difference between the certainty equivalent and the expected value of the lottery.

The hypothesis under investigation holds if the equality of risk premia is rejected.

Hypo.: Hypothetical

a: Comparison between real gains and "recoded" covered losses 
Table 4: Losses, Outcome Subpart. Median Certainty Equivalents (absolute values).

\begin{tabular}{|c|c|c|c|c|}
\hline & \multicolumn{4}{|c|}{ LOSSES } \\
\hline Question & Hypothetical & Real & Covered & -value $^{\mathrm{a}}$ \\
\hline$(-5,25 \% ; 0,75 \%)$ & 1.38 & 1.63 & 1.50 & 0.92 \\
$|\mathrm{EV}|=1.25$ & $(1.13-2.00)$ & $(1.13-2.13)$ & $(1.13-2.13)$ & \\
\hline$(-10,25 \% ; 0,75 \%)$ & 3.25 & 3.25 & 3.25 & 0.95 \\
$|\mathrm{EV}|=2.5$ & $(2.75-4.25)$ & $(2.75-3.75)$ & $(2.75-3.75)$ & \\
\hline$(-20,25 \% ; 0,75 \%)$ & 7.50 & 5.50 & 6.50 & 0.24 \\
$|\mathrm{EV}|=5$ & $(5.50-7.50)$ & $(5.50-7.50)$ & $(5.50-7.50)$ & 0.77 \\
\hline$(-10,25 \% ;-5,75 \%)$ & 6.50 & 6.63 & 6.63 & 0.56 \\
$|\mathrm{EV}|=6.25$ & $(6.13-7.13)$ & $(6.13-6.88)$ & $(6.13-6.63)$ & \\
\hline$(-15,25 \% ;-5,75 \%)$ & 8.19 & 8.25 & 8.00 & 0.46 \\
$|\mathrm{EV}|=7.50$ & $(7.25-8.75)$ & $(7.25-8.75)$ & $(7.25-8.75)$ & \\
\hline$(-20,25 \% ;-15,75 \%)$ & 16.44 & 16.63 & 16.63 & $(16.13-17.13)$ \\
\hline $\mathrm{EV} \mid=16.25$ & $(16.13-17.13)$ & $(16.13-16.88)$ & \\
\hline
\end{tabular}

Interquartile ranges are in parentheses.

EV: Expected Value. In the loss domain, risk aversion implies that, in absolute value, the certainty equivalent of the lottery is higher than its expected value.

a: Statistical significance of the difference between real, hypothetical and covered losses (Friedman test) 
Table 5: Gains, Outcome Subpart. Median Certainty Equivalents.

\begin{tabular}{|c|c|c|c|}
\hline \multicolumn{2}{|c|}{} & \multicolumn{2}{|c|}{ GAINS } \\
\hline Question & Hypothetical & Real & -value $^{a}$ \\
\hline$(15,25 \% ; 20,75 \%)$ & 18.19 & 18.00 & 0.37 \\
$|\mathrm{EV}|=18.75$ & $(17.88-18.63)$ & $(17.82-18.63)$ & 0.055 \\
\hline$(10,25 \% ; 20,75 \%)$ & 16.25 & 15.75 & 0.02 \\
$|\mathrm{EV}|=17.50$ & $(15.50-17.25)$ & $(15.25-16.75)$ & \\
\hline$(0,25 \% ; 20,75 \%)$ & 13.50 & 12.50 & 0.31 \\
$|\mathrm{EV}|=15$ & $(11.50-14.50)$ & $(9.50-14.50)$ & \\
\hline$(10,25 \% ; 15,75 \%)$ & 13.25 & 13.38 & 0.045 \\
$|\mathrm{EV}|=13.75$ & $(12.88-13.63)$ & $(12.88-13.88)$ & \\
\hline$(5,25 \% ; 15,75 \%)$ & 11.25 & 10.75 & 0.06 \\
$|\mathrm{EV}|=12.50$ & $(10.25-12.00)$ & $(9.75-11.75)$ & \\
\hline$(0,25 \% ; 5,75 \%)$ & 3.88 & 3.38 & $(2.88-3.88)$ \\
$|\mathrm{EV}|=3.75$ & $(3.13-4.00)$ & & \\
\hline
\end{tabular}

Interquartile ranges are in parentheses.

EV: Expected Value. In the gain domain, risk aversion implies that the certainty equivalent of the lottery is lower than its expected value.

a: Statistical significance of the difference between hypothetical and real gains (unilateral Wilcoxon test) 
Table 6: Estimation Results, Utility

\begin{tabular}{|l|c|c|c|c|c|}
\hline & \multicolumn{3}{|c|}{ LOSSES } & \multicolumn{2}{c|}{ GAINS } \\
\hline & Hypothetical & Real & Covered & Hypothetical & Real \\
\hline Utility & 1.09 & 0.99 & 1.06 & 0.96 & 0.95 \\
parameter & $(1.05-1.13)$ & $(0.95-1.03)$ & $(1.02-1.11)$ & $(0.90-1.00)$ & $(0.91-1.00)$ \\
\hline Error & 0.048 & 0.046 & 0.052 & 0.069 & 0.060 \\
parameter & $(0.046-0.051)$ & $(0.044-0.048)$ & $(0.049-0.054)$ & $(0.066-0.072)$ & $(0.058-0.064)$ \\
\hline Probability & 0.305 & 0.317 & 0.322 & 0.647 & 0.61 \\
weight & $(0.297-0.313)$ & $(0.309-0.325)$ & $(0.313-0.330)$ & $(0.638-0.656)$ & $(0.603-0.620)$ \\
\hline
\end{tabular}

95\% confidence intervals are in parentheses.

${ }^{\mathrm{a}}$ : $\mathrm{w}^{-}(0.25)$ for losses and $\mathrm{w}^{+}(0.75)$ for gains.

Table 7: Estimation Results, Probability Weights

\begin{tabular}{|c|c|c|c|c|c|}
\hline & \multicolumn{3}{|c|}{ LOSSES } & \multicolumn{2}{c|}{ GAINS } \\
\hline \multirow{2}{*}{$\mathbf{p = 5 \%}$} & Hypothetical & Real & Covered & Hypothetical & Real \\
& $\begin{array}{c}0.103 \\
(0.06-0.19)\end{array}$ & $\begin{array}{c}0.177 \\
(0.13-0.22)\end{array}$ & $\begin{array}{c}0.155 \\
(0.11-0.20)\end{array}$ & $\begin{array}{c}0.239 \\
(0.08-0.34)\end{array}$ & $\begin{array}{c}0.214 \\
(0.14-0.29)\end{array}$ \\
\hline $\mathbf{p = 2 5 \%}$ & 0.292 & 0.327 & 0.301 & 0.340 & 0.291 \\
& $(0.24-0.34)$ & $(0.28-0.43)$ & $(0.25-0.35)$ & $(0.24-0.49)$ & $(0.24-0.39)$ \\
\hline $\mathbf{p = 5 0 \%}$ & 0.494 & 0.467 & 0.502 & 0.489 & 0.490 \\
& $(0.39-0.55)$ & $(0.38-0.53)$ & $(0.40-0.55)$ & $(0.39-0.64)$ & $(0.34-0.54)$ \\
\hline $\mathbf{p = 7 5 \%}$ & 0.651 & 0.626 & 0.657 & 0.735 & 0.638 \\
& $(0.55-0.76)$ & $(0.53-0.73)$ & $(0.60-0.76)$ & $(0.59-0.78)$ & $(0.54-0.73)$ \\
\hline $\mathbf{p}=\mathbf{9 5 \%}$ & 0.757 & 0.776 & 0.814 & 0.879 & 0.832 \\
& $(0.70-0.86)$ & $(0.72-0.83)$ & $(0.71-0.87)$ & $(0.73-0.93)$ & $(0.74-0.93)$ \\
\hline
\end{tabular}

Interquartile ranges are in parentheses. 


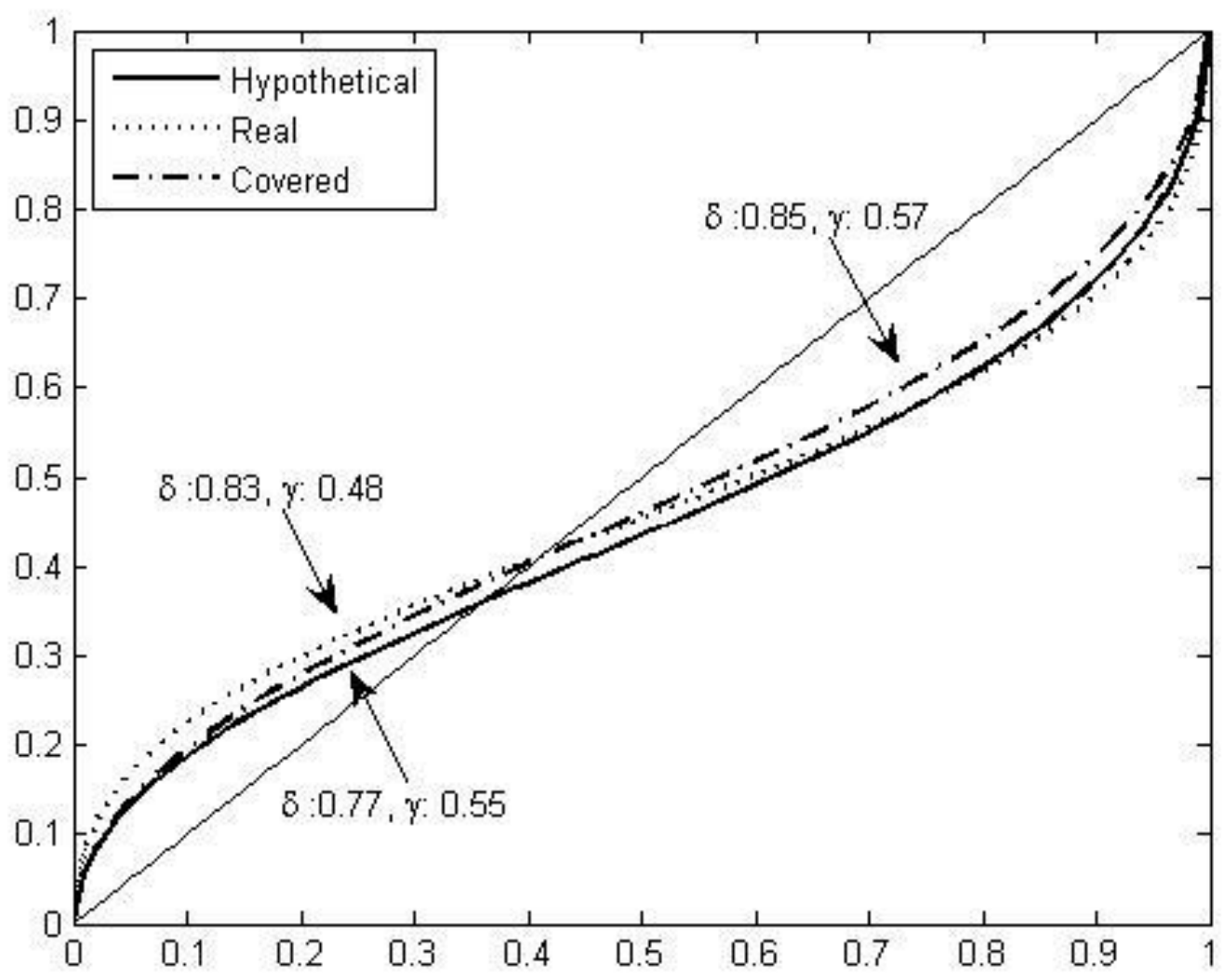

Figure 1: Estimation Results, Probability Weighting Functions, Losses 


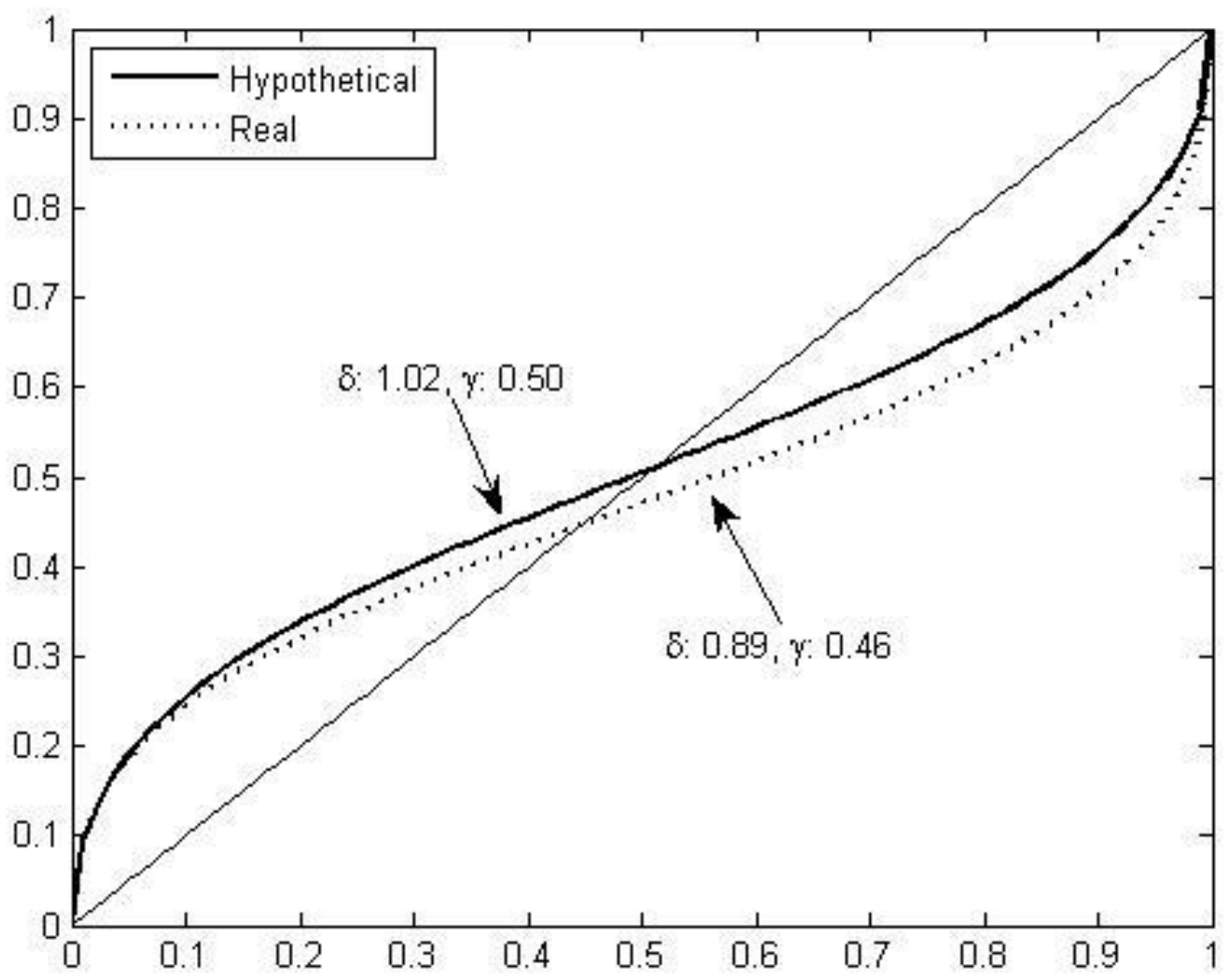

Figure 2: Estimation Results, Probability Weighting Functions, Gains 
Appendix A: A Typical Choice Situation

\begin{tabular}{|c|c|c|c|}
\hline \multicolumn{2}{|c|}{$\begin{array}{c}\text { Alternative A } \\
\text { (lottery) }\end{array}$} & \multicolumn{2}{|c|}{$\begin{array}{l}\text { Alternative B } \\
\text { (sure amount) }\end{array}$} \\
\hline & $\begin{array}{c}\text { I Choose } \\
\text { A }\end{array}$ & $\begin{array}{c}\text { I Choose } \\
\text { B } \\
\end{array}$ & \\
\hline \multirow{21}{*}{$\begin{array}{l}-5 € \\
75 \%\end{array}$} & & & $-5.00 €$ \\
\hline & & & $-5.50 €$ \\
\hline & & & $-6.00 €$ \\
\hline & & & $-6.50 €$ \\
\hline & & & $-7.00 €$ \\
\hline & & & $-7.50 €$ \\
\hline & & & $-8.00 €$ \\
\hline & & & $-8.50 €$ \\
\hline & & & $-9.00 €$ \\
\hline & & & $-9.50 €$ \\
\hline & & & $-10.00 €$ \\
\hline & & & $-10.50 €$ \\
\hline & & & $-11.00 €$ \\
\hline & & & $-11.50 €$ \\
\hline & & & $-12.00 €$ \\
\hline & & & $-12.50 €$ \\
\hline & & & $-13.00 €$ \\
\hline & & & $-13.50 €$ \\
\hline & & & $-14.00 €$ \\
\hline & & & $-14.50 €$ \\
\hline & & & $-15.00 €$ \\
\hline
\end{tabular}




\section{Appendix B: The Recoding Mechanism used for Building Each Gain Lottery}

To allow the testing of Assumption A1.2., the gain gambles had to be built from the loss ones using the following mechanism. Suppose that we use a losses-from-an-initial-endowment procedure with an initial endowment of $\mathrm{A}>0$. Now, consider a subject who is tempted to deal with covered losses as if they were real gains by integrating the initial endowment A into the subsequent losses she may undergo. As a result, when faced with the covered losses prospect $\mathrm{P}^{-}=(\mathrm{X}, \mathrm{p} ; \mathrm{Y}, 1-\mathrm{p})[$ with $-\mathrm{A} \leq \mathrm{X}<\mathrm{Y} \leq 0]$, she may behave as if she were actually confronting the positive prospect $\mathrm{P}^{+}=(\mathrm{X}+\mathrm{A}, \mathrm{p} ; \mathrm{Y}+\mathrm{A}, 1-\mathrm{p})$ [with $0 \leq \mathrm{X}+\mathrm{A}<\mathrm{Y}+\mathrm{A} \leq \mathrm{A}$.]. This "as if" (AI) Lottery $\mathrm{P}^{+}$is denoted $\mathrm{P}_{\mathrm{AI}}^{+}$. Now, let us denote $\mathrm{CE}^{-}$the certainty equivalent of the subject for $\mathrm{P}^{-}$, and $\mathrm{CE}_{\mathrm{AI}}^{+}$her "as if" certainty equivalent for $\mathrm{P}_{\mathrm{AI}}^{+} \cdot \mathrm{CE}_{\mathrm{AI}}^{+}$is thus given by $\mathrm{CE}_{\mathrm{AI}}^{+}=\mathrm{CE}^{-}$ + A. Note that the first formula assumes that the initial endowment is completely integrated into subsequent losses. If the integration process is only partial, $\mathrm{CE}_{\mathrm{AI}}^{+}$will be given by $\mathrm{CE}_{\mathrm{AI}}^{+}$ $=\mathrm{CE}^{-}+\mathrm{B}$, with $0<\mathrm{B}<\mathrm{A}$.

From an empirical point of view, we obviously can not observe whether a subject integrates her initial endowment into subsequent losses (be it partially or completely) or not. Nevertheless, we can in fact determine whether she does or not (and test Assumption A1.2.), by comparing her behavior in the covered losses condition, after recoding these losses as gains by integrating the initial endowment into subsequent losses, and her behavior in the corresponding real gains condition. More specifically, all we have to do is compare her "as if" certainty equivalent for $\mathrm{P}_{\mathrm{AI}}^{+}$, namely $\mathrm{CE}_{\mathrm{AI}}{ }^{+}$, with her certainty equivalent when facing the same lottery $\mathrm{P}^{+}$but under a "real gains" $(\mathrm{R})$ condition, denoted $\mathrm{CE}_{\mathrm{R}}{ }^{+}$.

To permit such a comparison, each of the 11 gain prospects $\mathrm{P}^{+}$has to be built as the positive counterpart of one of the 11 initial loss prospects $\mathrm{P}^{-}=(\mathrm{X}, \mathrm{p} ; \mathrm{Y}, 1-\mathrm{p})$, using the simple formula $\mathrm{P}^{+}=(\mathrm{X}+\mathrm{A}, \mathrm{p} ; \mathrm{Y}+\mathrm{A}, 1-\mathrm{p})$ where $\mathrm{A}$ is the initial endowment. 